\title{
Risk Factors for Non-communicable Diseases among Adults of 25-65 Years at Kakamega County General Hospital, Kenya
}

\author{
Monicah Njambi Kibe, Gordon Nguka, Silvenus Konyole \\ Department of Nutritional Sciences, Masinde Muliro University of Science and Technology, Kenya
}

\begin{tabular}{l}
\hline Article Info \\
\hline Article history: \\
Received Jul 19, 2018 \\
Revised Oct 20, 2018 \\
Accepted Oct 27, 2018 \\
\hline
\end{tabular}

\section{Keyword:}

Adults

Anthropometrics

Cardiovascular diseases

Lipid parameters

Non-communicable diseases

\begin{abstract}
In Kenya the growing number of premature deaths with half of all hospital admissions and $33 \%$ of all deaths are associated with Non-communicable diseases. The study determined the physical measurements and lipid parameters of adults 25-65 years at Kakamega County General Hospital. Data was collected using the WHO STEPs Instrument: Physical measurements assessed were Mid Upper Arm Circumference, Waist Hip measurements, Body mass Index and blood pressure. The study significance level was 0.05. Data was analyzed using SPSS version 20. Descriptive statistics was used. $\chi^{2}$ test of independence was used to find out the relationship between anthropometric measurements and lipid parameters. Data was presented in form of tables, figures and texts. There was a significant relationship between BMI and Triglyceride $\chi^{2}(12, \mathrm{~N}=60)=25.752$ $\mathrm{P}=0.012$, BMI and $\operatorname{LDL} \chi^{2}(8, \mathrm{~N}=60)=19.312 \mathrm{p}=0.013$, BMI and Total Cholesterol $\chi^{2}(8, \mathrm{~N}=60)=18.694 \mathrm{p}=0.017$, MUAC and HDL $\chi^{2}(4, \mathrm{~N}=60)$ $=14.446 \mathrm{p}=0.006$, WHR and Total Cholesterol $\chi^{2}(2, \mathrm{~N}=60)=17.985 \mathrm{p}=0.000$, WHR and LDL $\chi^{2}(2, N=60)=15.246 \mathrm{p}=0.000$. The study advocated for policies to reduce the incidences of risk factors for NCDs which will assist in achievement of Sustainable Development Goals. Kenyan population are in need of screening for risks associated with NCDs.
\end{abstract}

Copyright $(0) 2018$ Institute of Advanced Engineering and Science. All rights reserved.

\section{Corresponding Author:}

Monicah Njambi Kibe,

Department of Nutritional Sciences,

Masinde Muliro University of Science and Technology,

P.O. Box 190-50100 Kakamega-Webuye Road, Kenya.

Email: monicak.kibe@gmail.com

\section{INTRODUCTION}

Globally 2.8 million people die annually as a result of being overweight or obese and 35.8 million disability-adjusted life years are due to overweight and obesity [1]. STEPS 2015 indicates that prevalence of overweight and obesity has increased drastically especially among women having $38 \%$ overweight and $14 \%$ obese in all the Kenyan counties [2]. While weight loss alone can improve on markers of Cardiovascular diseases (CVDs), manipulating dietary macronutrients contents contributes to the beneficial effects of weight loss and furthers the improvement of lipid profile even without alteration of total caloric intake [3]. CVDs are caused by atherosclerosis which result due to high intake of cholesterol which causes narrowing of blood vessels with blood lipids being cardiovascular health indicators [4]. The concentration of plasma lipoproteins is influenced by both quantity and quality of fats consumed and its balance is more important than total dietary fats consumed [5].

NCDs are the single cause of preventable illnesses, disability and mortality worldwide which greatly impact on productive capacity [6]. Accelerating burden of NCDs in developing countries is now a public health concern causing approximately 8.4 million deaths annually distributed worldwide irrespective of social economic status with increasing trend in LMICs [7]. NCDs account for $27 \%$ of deaths in Kenya, totaling almost 100,000 people per year [8]. Hypercholesterolemia is more prevalent in high income groups 
than middle and low income groups [9]. In a study among young adults of 18-25 years showed that paternal education was associated with a lower BMI and a better lipid profile [10]. A study by Omotoye showed that education and income has positive correlation with LDL-C, Triglycerides and Total Cholesterol but have a negative association with HDL-C [11]. The study aimed to show the relationship between anthropometrics and lipid parameters of Kenyans in Kakamega County.

\section{RESEARCH METHOD}

The study was located at Kakamega County General Hospital among 60 adults of $25-65$ years as a cross-sectional analytical study design where quantitative method of data collection was used. The study included adults of 25-65 years who agreed to participate. People excluded from the study were those having any of the conditions; diabetes, hypertension and cardiovascular diseases. Random sampling was used to identify the target population and purposive sampling was used to determine those not suffering from the mentioned conditions. This study was approved by Masinde Muliro University of Science and Technology Institutional Review Board (MMUST IRB) and permit was given by National Commission for Science, Technology and Innovation (NACOSTI/P/17/98745/19074). A written consent was obtained from the participants upon their agreement. Principles of ethics were observed throughout the study; beneficence was achieved by aiming for benefits from the study to the community, justice was achieved by random sampling, and non-malfeasance was observed by minimizing harm from the study. Autonomy and confidentiality of the data were maintained by coding the data and avoidance of use of participant's names.

Data was collected using WHO STEPs instrument which is the tool used to collect data and measure NCDs. The World Health Organization STEPs Instrument covered 2 different levels or steps of risk factor assessment: Step 2: Physical Measurement-Anthropometric measurements such as height and weight using Stadiometer, waist-hip measurements with tape measure, Mid Upper Arm circumference using MUAC tape and Blood Pressure using sphygmomanometer, Step 3: Biochemical measurements; lipid panel. Weight measurements was taken using a portable standard scale with subjects wearing only light clothing and no shoes. Body weight was taken using a scale to the nearest $0.1 \mathrm{~kg}$. The weighing scale was calibrated every day before the assessment. Body height in centimeters was taken with the subjects stand with their heels, buttocks, and heads against a wall. A flat object was placed on top of the object's head and their height was marked on tape affixed to the wall.

Body Mass Index was calculated as body weight in kilograms divided by square of body height in meters. Waist circumference was taken midpoint between the lower margin palpable rib and the top of iliac crest in a horizontal plane. Hip circumference was measured around the pelvic at point of maximal protrusion of the buttocks. For both Waist Circumference and Hip Circumference subjects were instructed to stand with arms at the sides, feet positioned close together, and weight evenly distributed across the feet. Circumference was measured at the end of a quiet expiration of the subject to the nearest $0.1 \mathrm{~cm}$. Waist Hip Ratio (WHR) was calculated by dividing Waist Circumference by Hip Circumference. Waist and hip circumference was done using a tape measure in $\mathrm{cm}$. Lipid parameters [Triglyceride (TG), Low Density Lipoprotein-Cholesterol (LDL-C), High Density Lipoprotein-Cholesterol (HDL-C) and Total Cholesterol (TC)] were assessed using Cardio-Check Professional Analyzer (PA) Machine. Data was analyzed using Statistical Package for Social Sciences (SPSS) version 20 software. Descriptive statistics and inferential statistics were used in the analysis. Descriptive statistics of central tendency was used obtain frequencies and percentages of anthropometrics measures and lipid parameters. Relationship between anthropometrics and lipid parameters was obtained using $\chi^{2}$ statistic of independent. Significance levels was tested at 0.05 .

\section{RESULTS AND DISCUSSION}

The study was done to determine the risk factors for NCDs among adults 25-65 years at Kakamega County General Hospital. Variables studied included social demographic characteristics such as age, sex, education level, income level and type of occupation. Anthropometrics assessed included, MUAC, Waist and Hip Circumference (WHR), Weight and Height (BMI), and total body fat percentage. Biochemical measurements assessed was lipid profile including Triglycerides, HDL-C, LDL-C and Total Cholesterol.

Results on socio demographic characteristics indicated that majority of the participants were females $(67.3 \%)$ with half of the participants being youths 26-35 years (50.0\%). A good number of the participants had formal education with the majority having college/university education (73.3\%). In terms of marital status about half of the participants were married (56.7\%). Thirty-three point three percent $(33.3 \%)$ of the participants were government employees and $33.3 \%$ of the participants had no any source of income. 


\subsection{Anthropometrics measurements}

\subsubsection{Body mass index (BMI)}

Forty-three point four percent $(43.4 \%)$ of the participants were overweight $\left(25.0-29.9 \mathrm{~kg} / \mathrm{m}^{2}\right), 33.3 \%$ had normal BMI $\left(18.6-24.9 \mathrm{~kg} / \mathrm{m}^{2}\right), 16.7 \%$ were obese $\left(\geq 30.0 \mathrm{~kg} / \mathrm{m}^{2}\right), 3.3 \%$ were underweight $\left(17.1-18.5 \mathrm{~kg} / \mathrm{m}^{2}\right)$ and $3.3 \%$ with a BMI of $\left(<17.0 \mathrm{~kg} / \mathrm{m}^{2}\right)$ were moderately underweight. Almost half of the participants were overweight with a BMI of $25.0-29.9 \mathrm{~kg} / \mathrm{m}^{2}$ shown in Figure 1. Regular physical activity contribute the avoidance of overweight and hence to the prevention of dyslipidemia [12].

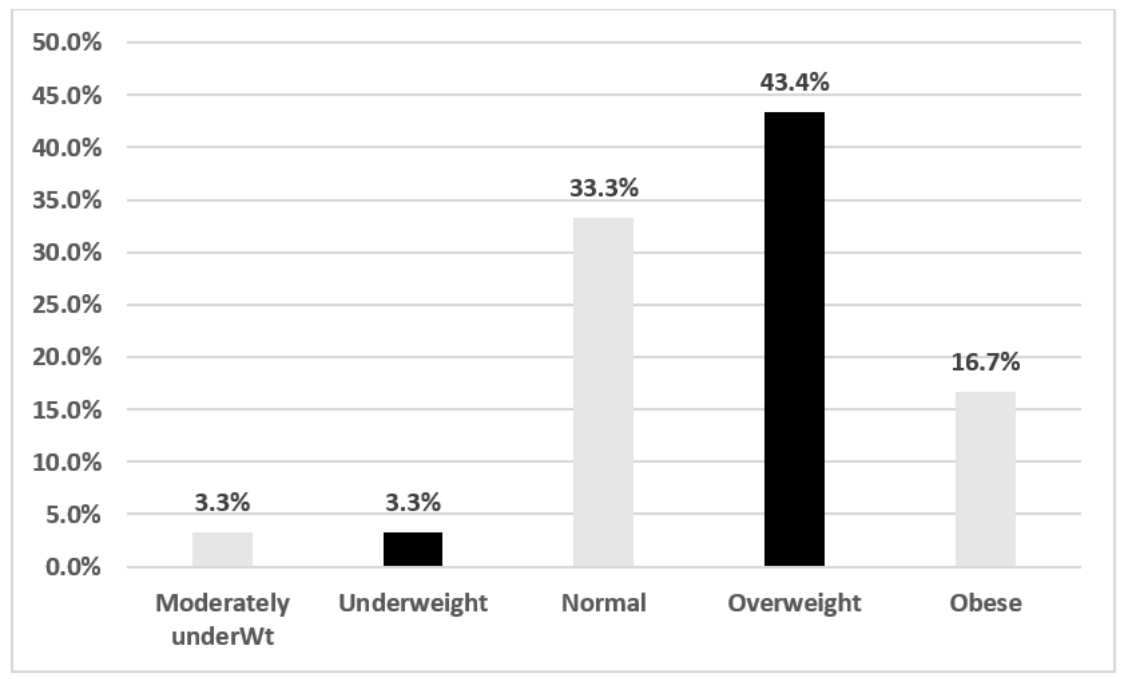

Figure 1. Body mass index measurements

\subsubsection{Waist hip ratio measurements}

Seventy-three point three percent $(73.3 \%$ ) had normal waist hip ratio of $\leq 0.88,26.7 \%$ of the participants had high waist hip Ratio measurements ( $>0.82$ for females and $>0.94$ for males). More than half at $73.3 \%$ of the participants had normal waist hip ratio measurements shown in Figure 2.

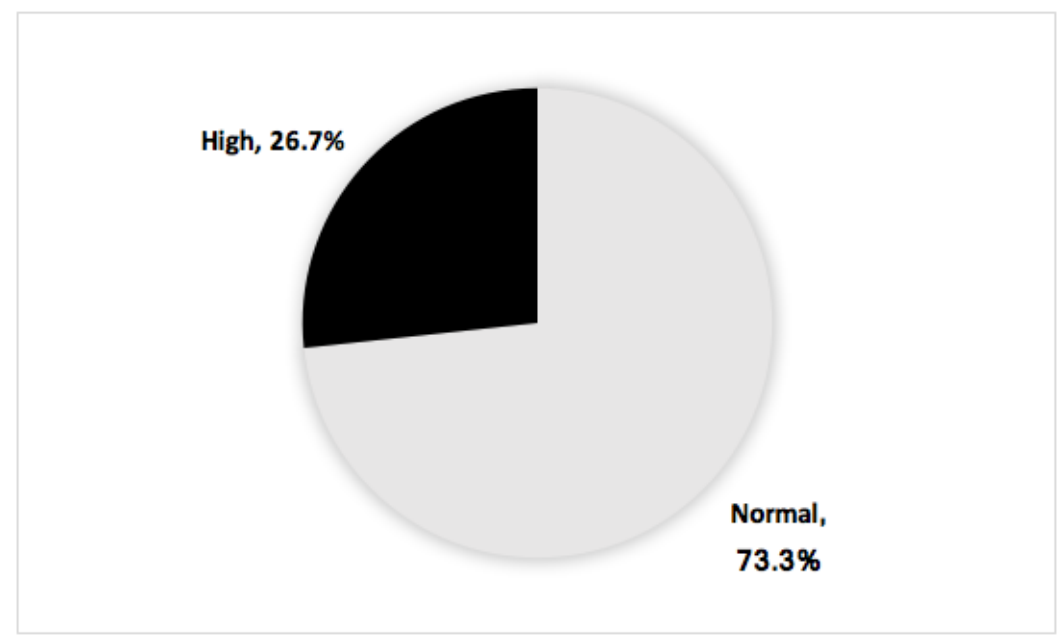

Figure 2. Waist Hip Ratio measurements 


\subsubsection{Total body fat percentage (TBF \%) measurements}

Ninety percent $(90.0 \%)$ of the participants had high total body fat percentage, $6.7 \%$ had normal and $3.3 \%$ had low total body fat percentage. Results shows majority of the participants $90 \%$ had high levels of total body fat percentage shown in Figure 3.

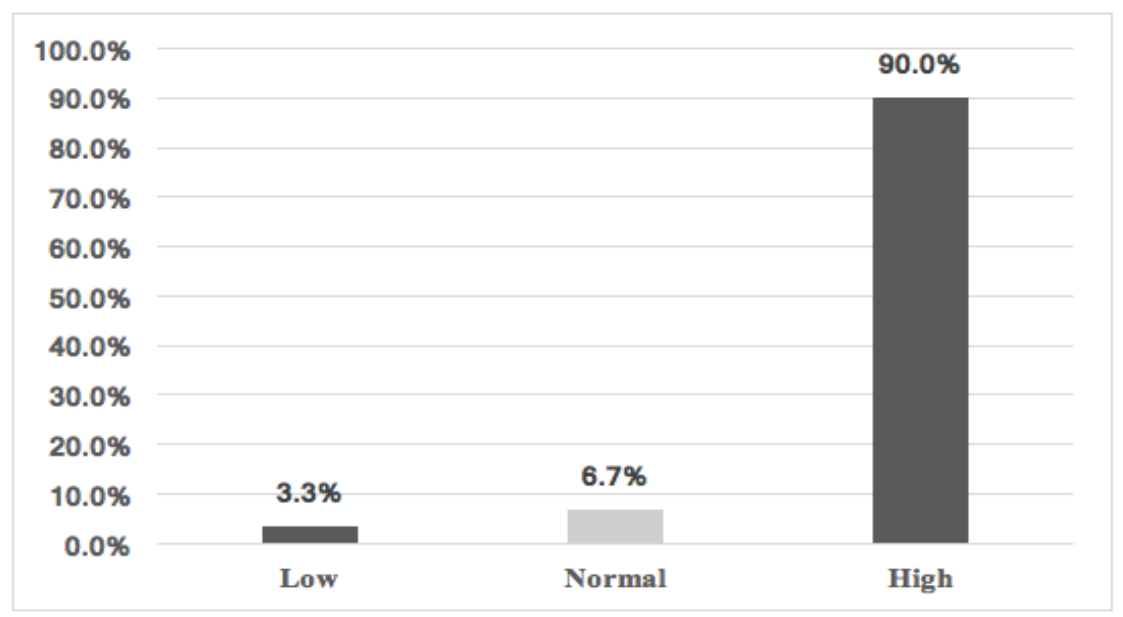

Figure 3. Total body fat percentage (TBF \%) measurements

\subsubsection{Mid upper arm circumference measurements}

Forty percent $(40.0 \%)$ of the participants were overweight $(28.3-31.6 \mathrm{~cm}), 30.0 \%$ were normal $(24-28.1 \mathrm{~cm})$ and $20.0 \%$ were obese $(>31.7 \mathrm{~cm}), 6.7$ were underweight $(23-23.9 \mathrm{~cm})$ and $3.3 \%$ were moderately underweight $(<22.9 \mathrm{~cm})$ in terms of Mid Upper Arm Circumference measurements. Almost half of the participants $40.0 \%$ were overweight shown in Figure 4.

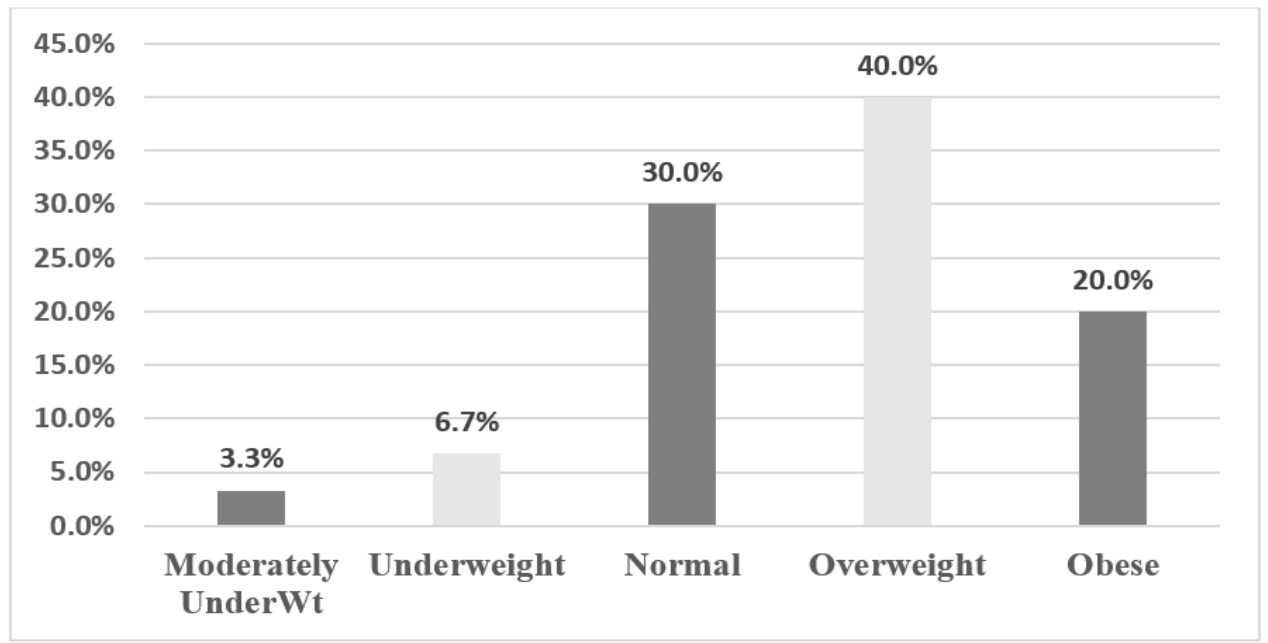

Figure 4. Mid upper arm circumference measurements

\subsection{Blood pressure measurements}

Physiological measurements of Blood pressure showed $40.0 \%$ of the participants had optimal systolic blood pressure of $<120 \mathrm{mmHg}$ and about $23.4 \%$ had mild hypertension (140-159mmHg). Diastolic blood pressure measurements showed that $60.0 \%$ of the participants had optimal diastolic blood pressure of $<80 \mathrm{mmHg}$ with $16.7 \%$ having high normal levels $86-89 \mathrm{mmHg}$. Table 1 . The study observed that the population under study was at risk of hypertension. Systolic pressure showed that $23.4 \%$ had mild hypertension (140-159 $\mathrm{mmHg}$ ) and 3.3\% had moderate hypertension of 160-179mmHg. Diastolic pressure 
measurements showed that $16.7 \%$ had high normal levels $86-89 \mathrm{mmHg}$ and $10.0 \%$ had mild hypertension Table 1. The results revealed a great health risk since the population under investigation has never been diagnosed of hypertension. The result correlate with those of Nugent and Brouwer who found out that hypertension in both male and female in Kenya ranges from $7.4 \%$ to $21.4 \%$ in rural areas and $12.3 \%$ and $22.8 \%$ in urban areas. The risk of hypertension can be explained by a study which found out that tobacco produces substances that narrow or damage the blood vessels which causes plague to form at a faster rate [13]. In Kenya awareness among those who have hypertension is low and successful management is even lower [14]. Nugent \& Brouwer also observed a challenge; if hypertension stays unmanaged it would cause 33,600 deaths by 2030 [14].

Table 1. Blood Pressure Measurements

\begin{tabular}{clc}
\hline \multicolumn{1}{c}{ Variable } & \multicolumn{1}{c}{ Measurement value } & $(\%)$ \\
\hline Systolic Blood pressure & Optimal -<120mmHg & 40.0 \\
& Normal -121-130mmHg & 23.3 \\
& High Normal -130-139mmHg & 10.0 \\
& Mild Hypertension(HTN) $-140-159 \mathrm{mmHg}$ & 23.4 \\
& Moderate HTN-160-179mmHg & 3.3 \\
Diastolic Blood pressure & Optimal-<80mmHg & 60.0 \\
& Normal-81-85mmHg & 13.3 \\
& High Normal-86-89mmHg & 16.7 \\
& Mild HTN & 10.0 \\
\hline
\end{tabular}

\subsection{Lipid parameters measurements}

\subsubsection{Total body cholesterol}

Eighty three point three percent $(83.3 \%)$ of the participants had desirable total cholesterol $(<5.18 \mathrm{mmol} / \mathrm{L}), 10.0 \%(\mathrm{n}=6)$ had borderline to high total cholesterol $(5.19-6.20 \mathrm{mmol} / \mathrm{L})$ and $6.7 \%$ of the participants had high total cholesterol levels of $>6.21 \mathrm{mmol} / \mathrm{L}$. Majority of the participants $(83.3 \%)$ had desirable total cholesterol levels shawn in Figure 5. Increasing levels of cholesterol leads to cardiovascular diseases and stroke due to increased LDL-C which undergoes oxidative modification in presence of free radicals [15].

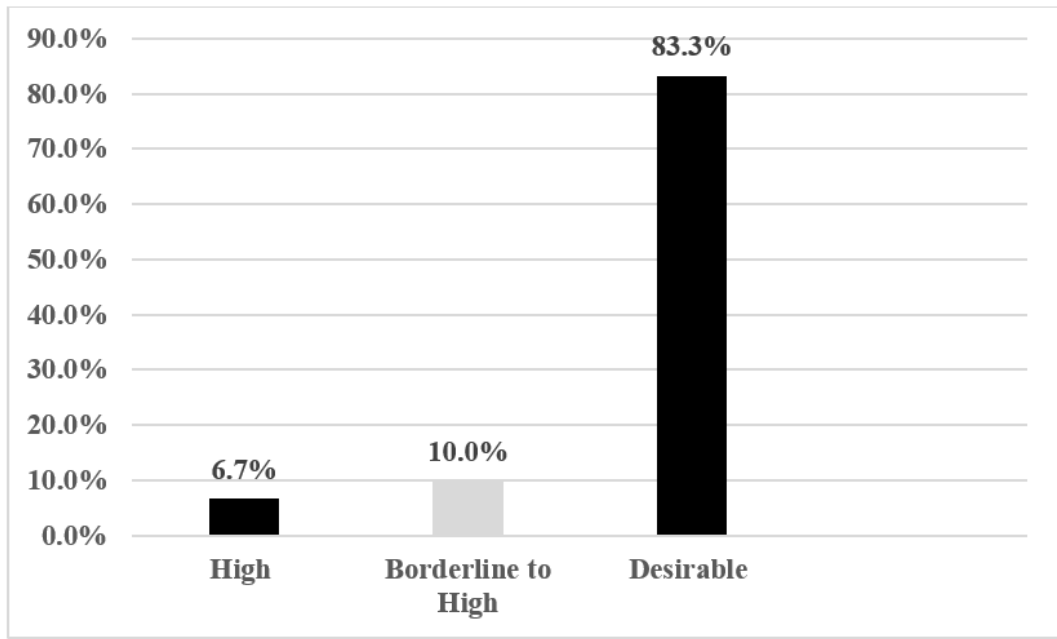

Figure 5. Total body cholesterol

\subsubsection{High density lipoprotein}

Seventy-three point three percent $(73.3 \%)$ of the participants had low High Density Lipoprotein Cholesterol levels of $<1.04 \mathrm{mmol} / \mathrm{L}$ and $26.7 \%(\mathrm{n}=16)$ had optimal levels of HDL $(1.05-1.55 \mathrm{mmol} / \mathrm{L})$. A big number of the participants had low levels of HDL shown in Figure 6. 


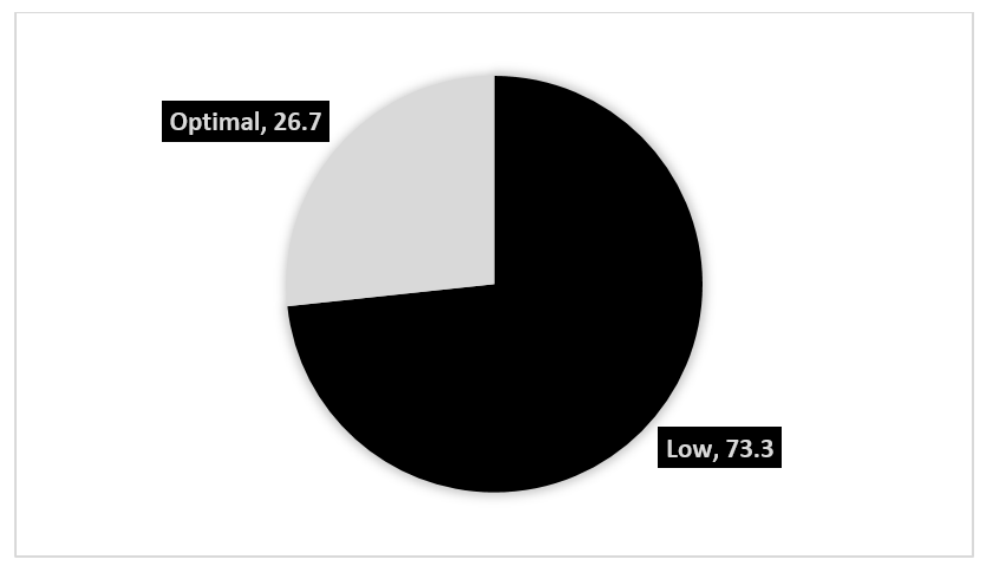

Figure 6. High Density Lipoprotein Cholesterol

\subsubsection{Low density lipoprotein cholesterol}

Eighty percent $(80.0 \%)$ had optimal LDL $(<2.59 \mathrm{mmol} / \mathrm{L}), 13.3 \%$ had near optimal levels $(2.60-3.35 \mathrm{mmol} / \mathrm{L})$, about $6.7 \%$ of the participants had high levels of $(4.14-4.90 \mathrm{mmol} / \mathrm{L})$. Almost half of the participants had optimal levels of LDL-C shown in Figure 7. A study by Shohaimi found out that LDL-C level were higher among women than men [16].

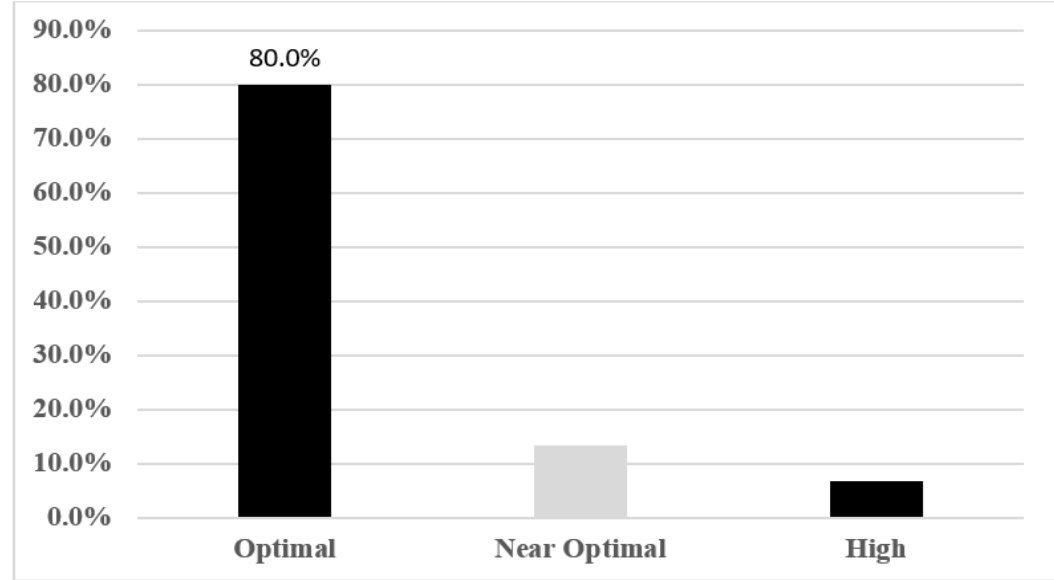

Figure 7. Low Density Lipoprotein Cholesterol

\subsubsection{Triglyceride levels}

Half of the participants $(50.0 \%)$ had normal triglyceride levels $(<1.70 \mathrm{mmol} / \mathrm{L})$. Twenty six point seven percent $(26.7 \%)$ had high levels of $(2.26-5.64 \mathrm{mmol} / \mathrm{L}), 20.0 \%$ had borderline to high levels $(1.71-2.25 \mathrm{mmol} / \mathrm{L})$ and $3.3 \%$ had very high triglyceride levels of $>5.65 \mathrm{mmol} / \mathrm{L}$. Half of the participants had normal levels of triglyceride shown in Figure 8. 


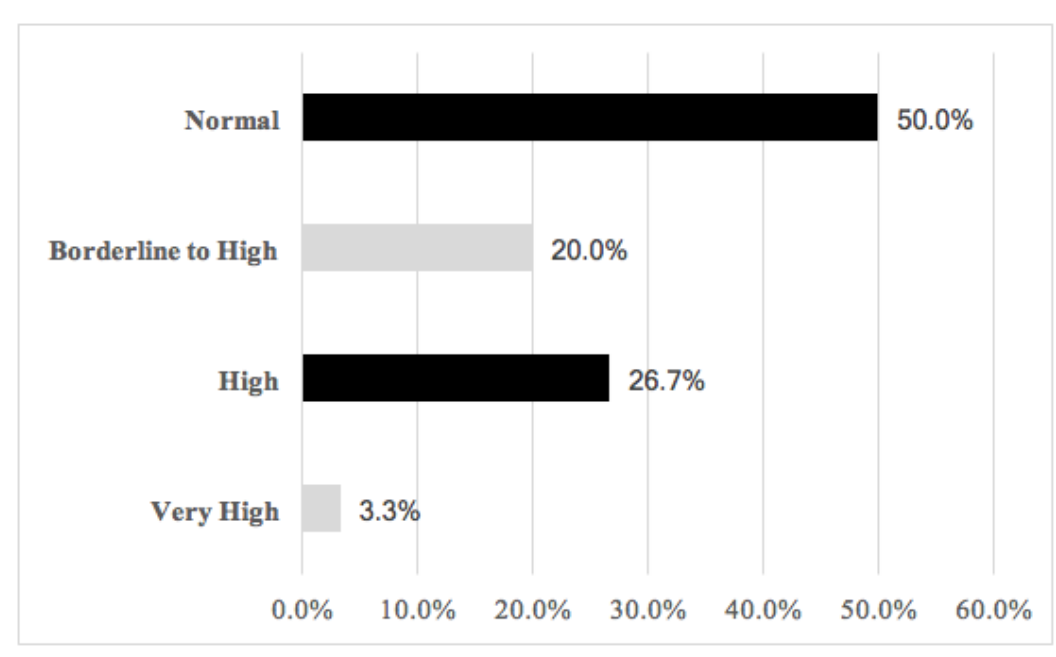

Figure 8. Triglyceride levels

\subsection{Association between anthropometrics and lipid parameters}

Significant relationship was observed between BMI and Triglyceride $(\mathrm{p}=0.012)$. There was significant relationship between BMI and Low Density Lipoprotein Cholesterol $(\mathrm{p}=0.013)$. There was significant relationship between BMI and Total Cholesterol $(\mathrm{p}=0.017)$ and no significant relationship was observed between BMI and HDL-C $(\mathrm{p}=0.177)$. MUAC was associated with HDL $(\mathrm{p}=0.006)$ and no association was seen between MUAC and LDL $(\mathrm{p}=0.105)$, Total Cholesterol $(\mathrm{p}=0.266)$ and Triglyceride $(p=0.103)$. There was significant association between Waist Hip Ratio and Total Cholesterol $(p=0.000)$, with LDL ( $\mathrm{p}=0.000)$ and no significant relationship was observed between Waist Hip Ratio and triglyceride and HDL ( $\mathrm{p}=0.677$ and $\mathrm{p}=0.263$ ) respectively. Total body fat percentage was not associated with any of the lipid parameters shown in Table 2.

Table 2. Association between Anthropometrics and Lipid Parameters

\begin{tabular}{lccc}
\hline \multicolumn{1}{c}{ BMI } & $\chi^{2}$ & $\mathrm{df}$ & $\mathrm{p}$ \\
\hline Triglyceride & 25.752 & 12 & 0.012 \\
LDL & 19.312 & 8 & 0.013 \\
HDL & 6.317 & 4 & 0.177 \\
Total Cholesterol & 18.694 & 8 & 0.017 \\
MUAC & & & \\
LDL & 13.205 & 8 & 0.105 \\
Triglyceride & 18.429 & 12 & 0.103 \\
HDL & 14.446 & 4 & 0.006 \\
Total Cholesterol & 9.993 & 8 & 0.266 \\
WHR & & & \\
Total Cholesterol & 17.985 & 2 & 0.000 \\
HDL & 1.225 & 1 & 0.263 \\
Triglyceride & 1.524 & 3 & 0.677 \\
LDL & 15.246 & 2 & 0.000 \\
Total Body fat percentage & & & \\
LDL & 3.224 & 4 & 0.521 \\
Triglyceride & 8.837 & 4 & 0.065 \\
HDL & 4.526 & 2 & 0.104 \\
Total Cholesterol & 2.623 & 4 & 0.623 \\
\hline
\end{tabular}

Mid Upper Arm Circumference was associated with HDL $(\mathrm{p}=0.006)$ and no association was seen between MUAC and LDL-C $(\mathrm{p}=0.105)$, Total Cholesterol $(\mathrm{p}=0.266)$ and Triglyceride $(\mathrm{p}=0.103)$. There was significant association between WHR and Total Cholesterol $(p=0.000)$ and with LDL $(p=0.000)$. The significant association between Waist Hip Ratio and LDL and Total Cholesterol may be explained by the fact that central obesity is linked to visceral fats. No association was observed between WHR and triglyceride and HDL $(p=0.677$ and $p=0.263$ ) respectively. This differ with a study which observed that Low HDL-C showed a positive correlation with a higher Waist Hip Ratio [17]. Total body fat percentage had no significant relationship with any of the lipid parameters shown in Table 2. 
In the present study, Mid Upper Arm Circumference and total body fat percentage showed poor correlation with lipid parameters. This differs with a study done in Eastern India which showed that there was a weak correlation between BMI and lipid parameters and that among all the anthropometric variables used in the study Waist Circumference was the best correlated to lipid parameters [9].

BMI was associated with Triglyceride $(\mathrm{p}=0.012)$, with LDL $(\mathrm{p}=0.013)$, with total cholesterol $(\mathrm{p}=0.017)$ and no association was observed between BMI and HDL-C $(\mathrm{p}=0.177)$. The results correlate with a study among male students at Saudi Arabia which showed a positive correlation between BMI and Total Cholesterol and LDL while a negative correlation coexisted between BMI and HDL-C. [18]. Another study found out a BMI $\geq 25 \mathrm{~kg} / \mathrm{m} 2$ was negatively correlated to HDL-C [9]. BMI increases plasma Total Cholesterol, Triglycerides and LDL increases [12].

The study has contributed to the field of health by providing information on risk factors for NCDs and meeting recommendations that were proposed by other researchers; Souza recommended that studies that report on high prevalence of modifiable risk factors for dyslipidemia are important to restructure the prevention model for the diseases associated with dyslipidemia [17]. It has also solved a challenge that was noticed in addressing NCDs by World Health Organization in the 2015 NCDs County Capacity Survey; lack of population based surveillance and poor targeting of screening proogrammes [19].

The study advocates for the screening of the population at risk and unaware of their nutrition and health status. This will be of help in the economy development of the Kenyan government because health expenditure in Kenya stands at $6.2 \%$ of total health expenditure which is $0.4 \%$ of total gross domestic product of the Country. Preventing occurrence of NCDs will improve the economy and fight poverty that is a burden to many Kenyans. Households afflicted by NCDs have high chance of being impoverished and driven into poverty due to healthcare and treatment costs [20]. The study has contributed to achievement of recommendations made by researchers; obesity can be used to screen for dyslipidemia with other coexisting risk factors [12]

\section{CONCLUSION}

It is appropriate to conclude that Kakamega residents are at risk of cardiovascular diseases due to high levels of cardiovascular biomarkers having 73.3\% of the participants with low levels of HDL-C, 26.7\% of them having high triglyceride levels, 6.7\% LDL-C and 6.7\% high levels of Total Cholesterol. Among the participants $43.4 \%$ were overweight, $16.7 \%$ were obese an indicator of risk of poor cardiovascular system and thus increased risk of cardiovascular diseases and diabetes.

Studies of similar nature like the present should be conducted at the communities in order to identify population at risk of NCDs because the study has shown majority could be at risk but unaware. The study recommends the government to provide financial support to nutrition projects that are aiming at reducing and preventing the burden of NCDs because a number of people are not aware of these risk factors. More research should be done on NCDs especially clinical research.

\section{ACKNOWLEDGEMENTS}

The authors acknowledge all that played part to see the success of the present study. The University of Masinde Muliro University of Science and Technology for provision of reading materials and research skills through seminars and workshops. The patients for participating and cooperating throughout the study. Research assistance for their support.

\section{REFERENCES}

[1] N. P. Steyn and Z. J. Mchiza, "Obesity and the Nutrition Transition in Sub-Saharan Africa," Ann. N. Y. Acad. Sci Annals of the New York Academy of Sciences., vol. 1311, no. 1, pp. 88-101, 2014.

[2] G. of K. Kenya Ministry of Health, "Statistical Review of Progress towards the Mid-term Targets of the Kenya Health Sector Strategic Plan 2014-2018," 2016.

[3] E. Daoud, C. Scheede-bergdahl, and A. Bergdahl, "Effects of Dietary Macronutrients on Plasma Lipid Levels and the Consequence for Cardiovascular Disease," no. Cvd, pp. 201-213, 2014.

[4] M. Dashti, W. Kulik, F. Hoek, E. C. Veerman, M. P. Peppelenbosch, and F. Rezaee, "A phospholipidomic Analysis of All Defined Human Plasma Lipoproteins," Scientific Reports, vol. 1, pp. 1-11, 2011.

[5] A. Hafiane and J. Genest, "High Density Lipoproteins: Measurement Techniques and Potential Biomarkers of Cardiovascular Risk," BBA Clinical., vol. 3, pp. 175-188, 2015.

[6] H. Fan and F. Song, "An Assessment of Randomized Controlled Trials (RCTs) for Non-communicable Diseases (NCDs): More and Higher Quality Research is Required in Less Developed Countries," Scientific Reports., vol. 5, no. July, pp. 1-10, 2015.

[7] T. Thippeswamy and C. Prathima, "Basic Risk Factors Awareness in Non-Communicable Diseases (BRAND)

Risk Factors for Non-communicable Diseases among Adults of 25-65 Years at... (Monicah Njambi Kibe) 
Study among People Visiting Tertiary Care Centre in Mysuru, Karnataka,” Journal of Clinical and Diagnostic Research., vol. 10, no. 4, pp. OC4-OC7, 2016.

[8] D. Some et al., "Task Shifting the Management of Non-Communicable Diseases to Nurses in Kibera, Kenya: does it work?," PLoS One, vol. 11, no. 1, pp. 1-9, 2016.

[9] G. Rajaram, "Effect of Dietary Fiber on Blood Lipid Profile of Selected Respondent," IFRJ International Food Research Journal, vol. 19, no. 1, pp. 297-302, 2012.

[10] T. H. Stea, M. Wandel, M. A. Mansoor, S. Uglem, and W. Frølich, "BMI, Lipid Profile, Physical Fitness and Smoking Habits of Young Male Adults and the Association with Parental Education," EJPH European Journal of Public Health, vol. 19, no. 1, pp. 46-51, 2018.

[11] F. E. Omotoye and G. T. Fadupin, "Effect of Body Mass Index on Lipid Profile of Type 2 Diabetic Patients at an Urban Tertiary Hospital in Nigeria," IOSR-JDMS, vol. 15, no. 9, pp. 65-70, 2016.

[12] R. Caroline et al., "Original Article Physical Activity and Lipid Profile in the ELSA- Brasil Study," Public Health, pp. 10-19, 2016.

[13] United Nations Development Programme., "Preventing and Controlling Non-Communicable Diseases," Issue Br., no. $62,2017$.

[14] R. Nugent and E. Brouwer, "Development Agenda Kenya Perspectives Diseases," 2015.

[15] M. Mahmoodi et al., "The Effects of Consumption of Raw Garlic on Serum Lipid Level, Blood Sugar and a Number of Effective Hormones on Lipid and Sugar Metabolism in Hyperglycemic and/or Hyperlipidemic Individuals," ABC, vol. 2011, no. August, pp. 29-33, 2011.

[16] S. Shohaimi, M. S. Boekholdt, R. Luben, N. J. Wareham, and K. T. Khaw, "Distribution of Lipid Parameters According to Different Socio-Economic Indicators- the EPIC-Norfolk Prospective Population Study," BMC Public Health, vol. 14, no. 1, pp. 1-10, 2014.

[17] J. D. De Souza et al., "Original/Ancianos Lipid Profile and Associated Factors among Elderly People, Attended at the Family Health Strategy, Viçosa/MG," vol. 32, no. 2, pp. 771-778, 2015.

[18] Al-ajlan, "Lipid Profile in Relation to Anthropometric Measurements among College Male Students in Riyadh, Saudi Arabia : A Cross-Sectional Study," Journal International of Biomedical Science, vol. 7, no. 2, pp. 112-119, 2011.

[19] World Health Organization, "Assessing National Capacity for the Prevention and Control of Noncommunicable Diseases: Report of the 2015 Global Survey," p. 130, 2015.

[20] D. Mwai and M. Muriithi, "Catastrophic Health Expenditure and Household Impoverishment: A Case of Prevalence of Non-Communicable Diseases in Kenya," EBPH Epidemiology, Biostatistics and Public Health., vol. 13, no. 1, pp. 1-7, 2016. 